Magna Scientia Advanced Research and Reviews

eISSN: 2582-9394

Cross Ref DOI: $10.30574 / \mathrm{msarr}$

Journal homepage: https://magnascientiapub.com/journals/msarr/

(REVIEW ARTICLE)

\title{
Potential impacts of future climate changes on agriculture
}

\author{
Abdulrazzaq Abdulhameed Al-Rawi * \\ emeritus, Iraq.
}

Magna Scientia Advanced Research and Reviews, 2021, 03(02), 087-094

Publication history: Received on 24 November 2021; revised on 27 December 2021; accepted on 29 December 2021

Article DOI: https://doi.org/10.30574/msarr.2021.3.2.0087

\begin{abstract}
Climatic change impacts on agriculture, livestock and human health are being witnessed all around the world. The agricultural sector is a driving force in the gas emissions and land use effects thought to cause climate change. The agricultural food system is responsible for a significant amount of greenhouse gas emissions. Food availability is the most important issue that takes the priority places in the policies of all countries all over the world. The climatic change could affect agriculture in several ways; among these ways are productivity (in terms of quantity and quality of crops); agricultural practices (through changes of water use and agricultural inputs such as herbicides, insecticides and fertilizers). Moreover, climate change could affect food security, insects, plant diseases and weeds as global warming could lead to an increase in pest insect populations, harming yields of crops like wheat, soybeans, and corn. While warmer temperatures create longer growing seasons, and faster growth rates for plants, it also increases the metabolic rate and number of breeding cycles of insect populations.
\end{abstract}

Keywords: Climate change; Agriculture; Food security; Insect; Crops; Greenhouse gas emissions.

\section{Introduction}

\subsection{Greenhouse Gas Emissions from Agriculture}

Climate change is defined as a long-term misbalance of weather conditions such as temperature, wind and rainfall characteristics and it is likely to be one of the main challenges that humankind will face in future. Climatic change impacts on agriculture and livestock are being witnessed all around the world. Furthermore, climate change, together with other natural and human-made health stressors, influences human health and disease in numerous ways. Some existing health threats will intensify and new health threats will emerge. The agricultural sector is a driving force in the gas emissions and land use effects thought to cause climate change. The agricultural food system is responsible for a significant amount of greenhouse gas emissions. Agriculture contributes to greenhouse gas increases through land use in four main ways:

- $\mathrm{CO}_{2}$ releases linked to deforestation

- Methane releases from rice cultivation

- Methane releases from enteric fermentation in cattle

- Nitrous oxide releases from fertilizer application

Together, these agricultural processes comprise 54\% of methane emissions, roughly $80 \%$ of nitrous oxide emissions, and virtually all carbon dioxide emissions tied to land use. The planet's major changes to land cover since 1750 have resulted from deforestation in temperate regions: when forests and woodlands are cleared to make room for fields and pastures, which can result in either warming or cooling effects, depending on local conditions. Deforestation also

\footnotetext{
${ }^{*}$ Corresponding author: Abdulrazzaq Abdulhameed Al-Rawi emeritus, Iraq.

Copyright $(2021$ Author(s) retain the copyright of this article. This article is published under the terms of the Creative Commons Attribution Liscense 4.0.
} 
affects regional carbon reuptake, which can result in increased concentrations of $\mathrm{CO}_{2}$, the dominant greenhouse gas. Land-clearing methods such as slash and burn compound these effects by burning biomaterial, which directly releases greenhouse gases [1].

\section{Impact of Extreme Climate}

Food availability is the most important issue that takes the priority places in the policies of all countries all over the world. Nevertheless, many countries are major importers of food. The sustainability of the agricultural sector has been faced many problems due to lack of well define strategic plan, neglect, and mismanagement. Policy makers, community, and the international organizations emphasize the potential of agriculture for food production, job creation, and income generation; they also tend to consider the current food system problems because of an alleged low productivity that they relate to the existing system. In the report of the Intergovernmental Panel on Climate Change [2] indicated that the world might reach a threshold of global warms beyond which current agricultural practices can no longer support large human civilizations, by the middle of the 21st century. In 2019, it published reports in which it stated that millions already suffer from food insecurity due to climate change and predicted decline in global crop production of $2 \%-6 \%$ by decade. A 2021 study estimates that the severity of heat wave and drought impacts on crop production tripled over the last 50 years. Climate change induced by increasing greenhouse gases is likely to affect crops differently from region to region. More effects on yield tend to depend largely on efficiency in water use and decrease in water availability. In the long run, the climatic change could affect agriculture in several ways:

- Productivity, in terms of quantity and quality of crops,

- Agricultural practices, through changes of water use (irrigation) and agricultural inputs such as herbicides, insecticides and fertilizers,

- Environmental effects, in particular in relation of frequency and intensity of soil drainage (leading to nitrogen leaching), soil erosion, reduction of crop diversity,

- Adaptation, organisms may become more or less competitive, as well as humans may develop more competitive crops, such as flood resistant or salt resistant varieties of rice.

Rapid climate change, however, could harm agriculture in many countries, especially those that are already suffering from rather poor soil and climate conditions, because there is less time for optimum natural selection and adaption. Nevertheless, much remains unknown about exactly how climate change may affect farming and food security. In some cases, it seems that even minor droughts have big impacts on food security $[2,3,4]$. The complexity of the climate system itself and its relationship to agricultural resources make it difficult to project specific effects on individual country or community. Temperature increases can have both positive and negative effects on crop yields, with the difference depending in part on location and on the magnitude of the increase. For example, crop yields in the northern United States and Canada may increase, but yields in the already warm, are likely to decline. Evidence also suggests positive crop yield effects for mild to moderate temperature increases such as $2^{\circ} \mathrm{C}$ to $3^{\circ} \mathrm{C}$. However, once average global temperatures rise beyond about $4^{\circ} \mathrm{C}$, yields begin to fall. Increases in precipitation level, timing, and variability may benefit semi-arid and other water-short areas by increasing soil moisture, but could aggravate problems in regions with excess water. Higher carbon dioxide $\left(\mathrm{CO}_{2}\right)$ levels in controlled experiments increase crop growth and decrease water use. However, these experiments often have demonstrated a more positive response than observed under actual field conditions. Agricultural systems are most sensitive to extreme climatic events such as floods, windstorms, and droughts, and to seasonal variability such as periods of frost, cold temperatures, and changing rainfall patterns. Climate change could alter the frequency and magnitude of extreme events and could change seasonal patterns in both favorable and unfavorable ways, depending on regional conditions. Increases in rainfall intensity pose a threat to agriculture and the environment because heavy rainfall is primarily responsible for soil erosion, leaching of agricultural chemicals, and run off that carries livestock waste and nutrients into water bodies. Currently available climate forecasts cannot resolve how extreme events and variability will change; however, both are potential risks to agriculture. The rate of change is also uncertain. Adjustment costs are likely to be higher with greater rates of change. Farmers have a number of adaptation options open to them, such as changing planting and harvest dates, rotating crops, selecting crops and crop varieties for cultivation, consuming water for irrigation, using fertilizers, and choosing tillage practices. These adaptation strategies can lessen potential yield losses from climate change and improve yields in regions where climate change has beneficial effects. At the market level, price and other changes can signal further opportunities to adapt as farmers make decisions about land use and which crops to grow. Climate change can also have a number of negative indirect effects on agro-environmental systems effects that have been largely ignored in climate change assessments. These indirect effects include changes in the incidence and distribution of pests and pathogens, increased rates of soil erosion, and increased troposphere ozone levels from rising temperatures. Climate change is not expected to threaten the ability of some countries to produce enough food to feed their self through the next century; however, some other 
countries could see agricultural productivity fall. However, the form and pattern of change are uncertain because changes in regional climate cannot be predicted with a high degree of confidence. Nevertheless, farmers and the agricultural community must consider strategies that are economically and environmentally viable in the face of uncertainty about the course of climate change. As the temperature, changes and weather patterns become more extreme, areas, which were historically good for farmland will no longer be as amicable. The current prediction is for temperature increase and precipitation decrease for major arid and semi-arid regions (Middle East, Africa, Australia, Southwest United States, and Southern Europe). In addition, crop yields in tropical regions will be negatively affected by the projected moderate increase in temperature $\left(1-2^{\circ} \mathrm{C}\right)$ expected to occur during the first half of the century. During the second half of the century, further warming is projected to decrease crop yields in all regions including Canada and Northern United States. Many staple crops are extremely sensitive to heat and when temperatures rise over $36^{\circ} \mathrm{C}$, soybean seedlings are killed and corn pollen loses its vitality. Scientists project that an annual increase of $1{ }^{\circ} \mathrm{C}$ will in turn decrease wheat, rice and corn yields by $10 \%$. There are, however, some positive possible aspects to climate change as well. The projected increase in temperature during the first half of the century (1$3{ }^{\circ} \mathrm{C}$ ) is expected to benefit crop and pasture yields in the temperate regions. This will lead to higher winter temperatures and more frost-free days in these regions; resulting in a longer growing season, increased thermal resources and accelerated maturation. If the climate scenario results in mild and wet weather, some areas and crops will suffer, but many may benefit from this $[5,6]$. Moreover, extreme weather conditions continue to decrease crop yields in the form of droughts and floods. While these weather events are becoming more common, there is still uncertainty and therefore a lack of preparedness as to when and where they will take place. In extreme cases, floods destroy crops, disrupting agricultural activities, rendering workers jobless, and eliminating food supply. On the opposite end of the spectrum, droughts can also wipe out crops. It is estimated that $35-50 \%$ of the world's crops are at risk of drought. Agriculture employs the majority of the population in most low-income countries and increased costs can result in worker layoffs or pay cuts. Other farmers will respond by raising their food prices; a cost which is directly passed on to the consumer and affects the affordability of food. Some farms do not export their goods and their function is to feed a direct family or community; without that food, people will not have enough to eat. This results in decreased production, increased food prices, and potential starvation in parts of the world [7]. In addition, droughts have been occurring more frequently because of global warming and they are expected to become more frequent and intense in Africa, southern Europe, and the Middle East, most of the Americas, Australia, and Southeast Asia. Their impacts are aggravated because of increased water demand, population growth, urban expansion, and environmental protection efforts in many areas. Droughts result in crop failures and the loss of pasture grazing land for livestock.

One can conclude the most observed impacts are:

- $\quad$ Shifting in precipitation patterns; longer periods of both heavy rain and dryness.

- Increase in temperature average levels; hotter summers and warmer winters can affect plants cycles, and lead to early blooming, lesser pollination, and frost damage.

- Increase in flooding; causes crop damaging, water pollution, soil erosion.

- Increase in drought levels; affects plants survival and increase the risk of wildfires.

- Degraded soils; monoculture cropping systems turns soil into less organic rich environment, and more prone to erosion and water pollution.

- Crop factories; industrial agriculture lacks biodiversity, which affects plants viability.

- Heavy fertilizers and pesticides; cause water pollution, exposure to chemicals and higher costs for farmers.

According to the UN report Climate Change and Land: an IPCC special report on climate change, desertification, land degradation, sustainable land management, food security, and greenhouse gas fluxes in terrestrial ecosystems, food prices will rise by $80 \%$ by 2050 which will likely lead to food shortages. Some authors also suggest that the food shortages will probably affect poorer parts of the world far more than richer ones. To prevent hunger, instability, new waves of climate refugees, international help will be needed to countries who will miss the money to buy enough food and for also for stopping conflicts $[8,9,10]$.

\section{Effect of Climate Change on Food Security}

The Food and Agriculture Organization has estimated that in 2006, the number of people undernourished globally was 820 million. The agricultural market has become irreversibly global, and with most nations far behind on climate goals, the impact of climate change on farmers is unlikely to abate. What can geoscientists do to support more sustainable agriculture in current food-growing regions and maintain soil health in new growing areas? In some of the most foodinsecure regions of the world, it's difficult to pinpoint what actions are needed because food security research simply doesn't cover those areas. According to a recent study that text mined more than 16,000 abstracts from the food security 
literature, some of the most food-insecure regions of the world have very little presence in food security research, whereas some regions with high food security are overrepresented. Areas addressed in the current body of food security literature are not evenly spread across the globe. Some regions are overrepresented despite having high food security, whereas many food-insecure areas are underrepresented and need more attention. Regions with low food security that are well represented by current research practices likely have preexisting infrastructure to support academic research, like in eastern and western Africa. Agricultural stability depends on reliable, natural climate variations to bring seasonal shifts in weather. Climate will largely continue to affect food system through climate variability. Access to food is largely a matter of household and individual-level income and of capabilities and rights. Access has been affected by the thousands of crops being destroyed, how communities are dealing with climate shocks and adapting to climate change. Prices on food will rise due to the shortage of food production due to conditions not being favorable for crop production. Utilization is affected by floods and drought where water resources are contaminated, and the changing temperatures create vicious stages and phases of disease. Availability is affected by the contamination of the crops, as there will be no food process for the products of these crops as a result. Stability is affected through price ranges and future prices as some food sources are becoming scarce due to climate change, so prices will rise $[2,11]$.

\section{Insects, Plant Diseases and Weeds}

Global warming could lead to an increase in pest insect populations, harming yields of crops like wheat, soybeans, and corn. While warmer temperatures create longer growing seasons, and faster growth rates for plants, it also increases the metabolic rate and number of breeding cycles of insect populations. Insects that previously had only two breeding cycles per year could gain an additional cycle if warm growing seasons extend, causing a population boom. There are a few proposed solutions to the issue of expanding pest populations. One proposed solution is to increase the number of pesticides used on future crops. This has the benefit of being relatively cost effective and simple, but may be ineffective. Many pest insects have been building up an immunity to these pesticides. Another proposed solution is to utilize biological control agents. This includes things like planting rows of native vegetation in between rows of crops. This solution is beneficial in its overall environmental impact. Not only are more plants that are native being planted, but pest insects are no longer building up an immunity to pesticides. However, planting additional native plants requires more room, which destroys additional acres of public land. The cost is also much higher than simply using pesticides. Currently, pathogens take $10-16 \%$ of the global harvest and this level is likely to rise as plants are at an ever-increasing risk of exposure to pests and pathogens. Historically, cold temperatures at night and in the winter months would kill off insects, bacteria and fungi. The warmer, wetter winters are promoting fungal plant diseases like wheat rusts and soybean rust. Soybean rust is a vicious plant pathogen that can kill off entire fields in a matter of days, devastating farmers and costing billions in agricultural losses. Another example is the Mountain Pine Beetle epidemic in BC, Canada that killed millions of pine trees because the winters were not cold enough to slow or kill the growing beetle larvae. The increasing incidence of flooding and heavy rains also promotes the growth of various other plant pests and diseases. On the opposite end of the spectrum, drought conditions favor different kinds of pests like aphids, white flies and locusts. The competitive balance between plants and pests has been relatively stable for the past century, but with the rapidly shifting climate, there is a change in this balance that often favors the more biologically diverse weeds over the mono-crops. Currently, weeds claim about one tenth of global crop yields annually as there are about eight to ten weed species in a field competing with crops. Characteristics of weeds such as their genetic diversity, crossbreeding ability, and fast-growth rates put them at an advantage in changing climates as these characteristics allow them to adapt readily in comparison to most farms' uniform crops, and give them a biological advantage. There is also a shift in the distribution of pests as the altered climate makes areas previously uninhabitable more uninviting. When climate change leads to hotter weather, coupled with wetter conditions, this can result in more damaging locust swarms. Moreover, the fall armyworm, Spodoptera frugiperda, is a highly invasive plant pest that has in the recent years spread to countries in Sub-Saharan African. The spread of this plant pest is linked to climate change as experts confirm that climate change is bringing more crop pests to Africa and it is expected that these highly invasive crop pests will spread to other parts of the planet since they have a high capacity to adapt to different environments. The fall armyworm can have massive damage to crops, especially maize, which affects agricultural productivity [12,13].

A very important point to consider is that weeds would undergo the same acceleration of cycle as cultivated crops, and would benefit from carbonaceous fertilization. However, on the other hand, some results make it possible to think that weed killers could increase in effectiveness with the temperature increase. Global warming would cause an increase in rainfall in some areas, which would lead to an increase of atmospheric humidity and the duration of the wet seasons. Combined with higher temperatures, these could favor the development of fungal diseases. Similarly, because of higher temperatures and humidity, there could be an increased pressure from insects and disease vectors. Research has shown that climate change may alter the developmental stages of plant pathogens that can affect crops. Change in weather patterns and temperature due to climate change leads to dispersal of plant pathogens as hosts migrate to areas 
with more favorable conditions. This may increase more crop losses due to diseases. It has been predicted that the effect of climate change will add a level of complexity to figuring out how to maintain sustainable agriculture [14].

\section{Effect of Elevated Carbon Dioxide on Crops}

Elevated atmospheric carbon dioxide affects plants in a variety of ways. Elevated $\mathrm{CO}_{2}$ increases crop yields and growth through an increase in photosynthetic rate, and it decreases water loss because of stomatal closing. It limits the vaporization of water reaching the stem of the plant. Oxygen is all along the layer of the leaves for each plant leaves taking in $\mathrm{CO}_{2}$ and release $\mathrm{O}_{2}$. Today's concentration of $400 \mathrm{ppm}$ plants are relatively starved for nutrition. The optimum level of $\mathrm{CO}_{2}$ for plant growth is about 5 times higher. Increased mass of $\mathrm{CO}_{2}$ increases photosynthesis, this $\mathrm{CO}_{2}$ potentially stunts the growth of the plant. It limit's the reduction that crops lose through transpiration. Increase in global temperatures will cause an increase in evaporation rates and annual evaporation levels. Increased evaporation will lead to an increase in storms in some areas, while leading to accelerated drying of other areas. These storm impacted areas will likely experience increased levels of precipitation and increased flood risks, while areas outside of the storm track will experience less precipitation and increased risk of droughts. Water stress affects plant development and quality in a variety of ways first off drought can cause poor germination and impaired seedling development in plants. At the same time plant growth relies on cellular division, cell enlargement, and differentiation. Drought stress impairs mitosis and cell elongation via loss of turgor pressure that results in poor growth. Development of leaves is also dependent upon turgor pressure, concentration of nutrients, and carbon assimilates all of which are reduced by drought conditions, thus drought stress lead to a decrease in leaf size and number. Plant height, biomass, leaf size and stem girth has been shown to decrease in Maize under water limiting conditions. Crop yield is also negatively affected by drought stress, the reduction in crop yield results from a decrease in photosynthetic rate, changes in leaf development, and altered allocation of resources all due to drought stress. Crop plants exposed to drought stress suffer from reductions in leaf water potential and transpiration rate, however water-use efficiency has been shown to increase in some crop plants such as wheat while decreasing in others such as potatoes. Plants need water for the uptake of nutrients from the soil, and for the transport of nutrients throughout the plant, drought conditions limit these functions leading to stunted growth. Drought stress also causes a decrease in photosynthetic activity in plants due to the reduction of photosynthetic tissues, and reduced performance of photosynthetic machinery. This reduction in photosynthetic activity contributes to the reduction in plant growth and yields. Another factor influencing reduced plant growth and yields include the allocation of resources; following drought stress plants will allocate more resources to roots to aid in water uptake increasing root growth and reducing the growth of other plant parts while decreasing yields $[15,16]$.

\section{Erosion and Soil Degradation}

The warmer atmospheric temperatures observed over the past decades are expected to lead to a more vigorous hydrological cycle, including more extreme rainfall events. Erosion and soil degradation is more likely to occur. Soil fertility would also be affected by global warming. Increased erosion in agricultural landscapes from anthropogenic factors can occur with losses of up to $22 \%$ of soil carbon in 50 years. However, because the ratio of soil organic carbon to nitrogen is mediated by soil biology such that it maintains a narrow range, a doubling of soil organic carbon is likely to imply a doubling in the storage of nitrogen in soils as organic nitrogen, thus providing higher available nutrient levels for plants, supporting higher yield potential. The demand for imported fertilizer nitrogen could decrease, and provide the opportunity for changing costly fertilisation strategies. Due to the extremes of climate that would result, the increase in precipitations would probably result in greater risks of erosion, whilst at the same time providing soil with better hydration, according to the intensity of the rain. The possible evolution of the organic matter in the soil is a highly contested issue: while the increase in the temperature would induce a greater rate in the production of minerals, lessening the soil organic matter content, the atmospheric $\mathrm{CO}_{2}$ concentration would tend to increase it [17].

\section{Agricultural Policies That Promote Poverty Alleviation}

Researchers at the Overseas Development Institute (ODI) have investigated the potential impacts climate change could have on agriculture, and how this would affect attempts at alleviating poverty in the developing world. The vulnerability of the poor in developing countries to short-term impacts from climate change, notably the increased frequency and severity of adverse weather events is likely to have a negative impact. This should be taken into account when defining agricultural policy.

In developed countries, agriculture policy is often included several measures have been proposed:

- $\quad$ breeding more resilient crop varieties, and diversification of crop species 
- $\quad$ using improved agroforestry species

- $\quad$ capture and retention of rainfall, and use of improved irrigation practices

- Increasing forest cover and Agroforestry

- use of emerging water harvesting techniques (such as contour trenching)

However, in developing countries, where agriculture's share in global gross domestic product (GDP) is about 4\%. Therefore, in developing countries agricultural productivity remains low; poverty, vulnerability and food insecurity remain high; and the direct effects of climate change are expected to be especially harsh. Creating the necessary agricultural technologies and harnessing them to enable developing countries to adapt their agricultural systems to changing climate will require innovations in policy and institutions as well. In this context, institutions and policies are important at multiple scales. It was reported six policy principles: The best policy and institutional responses will enhance information flows, incentives and flexibility.

- Policies and institutions that promote economic development and reduce poverty will often improve agricultural adaptation and may also pave the way for more effective climate change mitigation through agriculture.

- $\quad$ Business as usual among the world's poor is not adequate.

- $\quad$ Existing technology options must be made more available and accessible without overlooking complementary capacity and investments.

- $\quad$ Adaptation and mitigation in agriculture will require local responses, but effective policy responses must also reflect global impacts and inter-linkages.

- $\quad$ Trade will play a critical role in both mitigation and adaptation, but will its elfbe shaped importantly by climate change.

State- or NGO-sponsored projects can help farmers be more resilient to climate change, such as irrigation infrastructure providing a dependable water source as rains become more erratic. Water catchment systems that collect water during the rainy season to be used during the dry season or periods of drought can also be used to mitigate the effects of climate change [18]. Moreover, Climate-smart agriculture (CSA) is an integrated approach to managing landscapes to help adapt agricultural methods, livestock and crops to the ongoing human-induced climate change and, where possible, counteract it by reducing greenhouse gas emissions, at the same time taking into account the growing world populationto ensure food security. Thus, the emphasis is not simply on sustainable agriculture, but also on increasing agricultural productivity. CSA ... is in line with FAO's vision for Sustainable Food and Agriculture and supports FAO's goal to make agriculture, forestry and fisheries more productive and more sustainable. CSA has three main pillars - increasing agricultural productivity and incomes; adapting and building resilience to climate change; and reducing and/or removing greenhouse gas emissions. CSA lists different actions to counter the future challenges for crops and plants. With respect to rising temperatures and heat stress, e.g. CSA recommends the production of heat tolerant crop varieties, mulching, water management, shade house, boundary trees and appropriate housing and spacing for cattle. There is a need to mainstream CSA into core government policies, expenditures and planning frameworks. In order for CSA policies to be effective, they must be able to contribute to broader economic growth, the sustainable development goals and poverty reduction. They must also be integrated with disaster risk management strategies, actions, and social safety net programs $[19,20]$.

\section{Conclusion}

It may concluded that climate change and agriculture are interrelated processes, both of which take place on a global scale, with the adverse effects of climate change affecting agriculture both directly and indirectly. This can take place through changes in average temperatures, rainfall, and climate extremes (e.g., heat waves); changes in pests and diseases; changes in atmospheric carbon dioxide and ground-level ozone concentrations; changes in the nutritional quality of some foods; and changes in sea level. Climate change is already affecting agriculture, with effects unevenly distributed across the world. Future climate changes will most likely affect crop production in low latitude countries negatively, while effects in northern latitudes may be positive or negative.In much of the world, climate change is altering regional growing conditions and making them more unpredictable. Farmers are finding it harder to consistently grow enough food to meet increasing demand. Securing the world's food supply for the future, experts assert, requires us to tally the good and the bad in the current agricultural structure, including the infrastructure and technology in food distribution systems. Small farms, which account for about $90 \%$ of the world's 570 million farms, are particularly vulnerable to changes in seasonal climate. Land tended by families for generations may suddenly become nonarable. A change in the timing or intensity of yearly rainy seasons could bring rains or drought that wipe out a family's crops. Financial and social inequality compound climate-related food security issues. Many of the world's 
smallholder farmers are poor and food insecure; even one lost season can push them from struggling to failing. Climate change plays a key role as a catalyzer in amplifying preexisting resource problems and will influence the quality and quantity of food we produce and our ability to distribute it equitably. It's not quite as simple as moving into less climateaffected areas. It remains an issue of climate and socioeconomic and technological development.

\section{Compliance with ethical standards}

\section{Acknowledgments}

Author thanks Abdulaziz Abdulhameed Abdulla for his help and support during preparing the article.

\section{References}

[1] IPCC. Refinement to the 2006 IPCC Guidelines for National Greenhouse Gas Inventories. Switzerland: IPCC. 2019.

[2] IPCC. The Intergovernmental Panel on Climate Change. United Nations body for assessing the science related to climate. 2021.

[3] Hoffmann U. Section B: Agriculture - a key driver and a major victim of global warming, in: Lead Article, in: Chapter 1, in Hoffmann. 2013;3(5).

[4] Blanco G. Section 5.3.5.4: Agriculture, Forestry, Other Land Use, in: Chapter 5: Drivers, Trends and Mitigation, in: IPCC AR5 WG3 2014, p. 383 Emissions aggregated using 100-year global warming potentials from the IPCC Second Assessment Report. 2014.

[5] Connor, Jeffery D, Schwabe Kurt, King Darran, Knapp, Keith. Irrigated agriculture and climate change: The influence of water supply variability and salinity on adaptation. Ecological Economics. 2012; 77: 149-157.

[6] Sindhu JS. Potential Impacts of Climate Change on Agriculture. Indian Journal of Science and Technology. 2011; 4(3): 348-353.

[7] Kristjanson Patti, Neufeldt Henry, GassnerAnja, et al. Are food insecure smallholder households making changes in their farming practices? Evidence from East Africa. Food Security. 2012; 4(3): 381-397.

[8] Rosenzweig C. Executive summary. In Parry MC, et al. (Eds.). Chapter 1: Assessment of Observed Changes and Responses in -Natural and Managed Systems. Climate change 2007: impacts, adaptation and vulnerability: contribution of Working Group II to the fourth assessment report of the Intergovernmental Panel on Climate Change. Cambridge University Press (CUP): Cambridge, UK: Print version: CUP. This version: IPCC website. Archived from the original on 2 November 2018.

[9] Dai A. Drought under global warming: A review. Wiley Interdisciplinary Reviews: Climate Change.2: 45-65. Bibcode. 2011.

[10] Ding Y, Hayes MJ, Widhalm M. Measuring economic impacts of drought: A review and discussion. Disaster Prevention and Management. 2011; 20(4): 434-446.

[11] Simelton E, Fraser E, Termansen M. Typologies of crop-drought vulnerability: an empirical analysis of the socioeconomic factors that influence the sensitivity and resilience to drought of three major food crops in China (1961-2001). Environmental Science \& Policy. 2009; 12(4): 438-452.

[12] Stange E. Climate Change Impact: Insects. Norwegian Institute for Nature Research. 2010.

[13] Chakraborty S, Newton AC. Climate change, plant diseases and food security: an overview. Plant Pathology. 2011; 60(1): 2-14.

[14] Coakley SM, Scherm H, Chakraborty S. Climate change and plant disease management. Annual Review of Phytopathology. 1999; 37: 399-426.

[15] Bhattacharya A. Effect of High Temperature on Crop Productivity and Metabolism of Macro Molecules. Academic Press. 2019.

[16] Fahad S, Bajwa AA, Nazir U, Anjum SA, Farooq A, Zohaib A, et al. Crop Production under Drought and Heat Stress: Plant Responses and Management Options. Frontiers in Plant Science. 2017; 8: 1147. 
[17] Roshydromet.Federal Service for Hydrometeorology and Environmental Monitoring (Roshydromet), Strategic Forecast of Climate Change in the Russian Federation 2010-2015 and Its Impact on Sectors of the Russian Economy. 2005.

[18] IPCC. Summary for Policymakers: C. Current knowledge about future impacts. In Parry ML, et al. (Eds.). Climate Change 2007: Impacts, Adaptation and Vulnerability. Contribution of Working Group II to the Fourth Assessment Report of the Intergovernmental Panel on Climate Change. Cambridge University Press. 2007.

[19] FAO. CLIMATE-SMART AGRICULTURE. Food and agriculture organization of the United Nations. 2013.

[20] OECD/FAO. 2016. OECD FAO Agricultural Outlook 20162025 (PDF). OECD Publishing. 59-61. 